RELACult - Revista Latino-Americana de Estudos em Cultura e Sociedade e-ISSN 2016/Atual: 2525-7870 | e-ISSN 2015/2016: 2447-018X

\title{
Agricultura familiar, agroecologia e desenvolvimento sustentável: análise fotográfica da revista Agroecologia e Desenvolvimento Rural Sustentável-EMATER/RS
}

Family farming, agro-ecology and sustainable development: photographic analysis of Agroecology and Sustainable Rural Development magazineEMATER/RS

La agricultura familiar, la agro-ecología y el desarrollo sostenible: análisis fotográfico de la revista Agroecología y Desarrollo Rural Sostenible-EMATER/RS

Me. João Gabriel da Silva Brito ${ }^{1}$

Dra. Betania Maciel ${ }^{2}$

\begin{abstract}
Resumo
O objetivo deste trabalho é analisar fotografias de agricultores familiares publicadas na revista Agroecologia e Desenvolvimento Rural Sustentável - EMATER/RS no período de 2000 a 2002. A revista Agroecologia e Desenvolvimento Rural Sustentável- EMATER/RS publica desde o ano 2000, artigos, entrevistas, relatos de experiência que debatem os conhecimentos e transformações no mundo rural por meio da luz da Agroecologia e do Desenvolvimento Rural Sustentável. Neste sentido, propomos uma discussão sobre agricultores familiares e desenvolvimento rural. Para embasar esta análise fotográfica, foram utilizados: análise documental, análise de conteúdo partindo da leitura de José de Souza Martins (2008) e Boris Kossoy (2008) que indicam maneiras e estratégias de apreciação de imagens fotográficas.
\end{abstract}

Palavras-chave: Agricultura familiar; desenvolvimento sustentável; agroecologia; EMATER/RS.

\section{Resumen}

El objetivo de este trabajo es analizar fotografías de agricultores familiares publicadas en la revista Agroecologia e Desenvolvimento Rural Sustentável-EMATER/RS en el periodo 2000 - 2002. La revista Agroecologia e Desenvolvimento Rural Sustentável-EMATER/RS publica, desde el año 2000, artículos, entrevistas y relatos de experiencias que debaten los conocimientos y transformaciones en el mundo rural por medio de la luz de la agroecología y del desarrollo rural sostenible. En este sentido, proponemos una discusión sobre los agricultores familiares y el desenvolvimiento rural. Para basar esta análisis fotográfica, fueron utilizados: análisis documental y análisis de contenido, partiendo de la lectura de José de Souza Martins (2008) y Boris Kossoy (2008) que indican maneras y estrategias de apreciaciones de imagines fotográficas.

Palabras-clave: Agricultura familiar; Desarrollo sostenible; Agroecología; EMATER/RS.

\footnotetext{
${ }^{1}$ Mestre em Extensão Rural e Desenvolvimento Local; Universidade Federal Rural de Pernambuco - UFRPE; Recife, Pernambuco, Brasil; jgmano@ hotmail.com.

${ }^{2}$ Doutora em Comunicação Social; Universidade Federal Rural de Pernambuco - UFRPE; Recife, Pernambuco, Brasil; betaniamaciel@gmail.com.
} 


\begin{abstract}
The objective of this reserch is analise some pictures from Family farmers published on the Agroecologia e Desenvolvimento Rural Sustentável - EMATER/RS magazine on the period 2000 to 2002. The Agroecologia e Desenvolvimento Rural Sustentável- EMATER/RS magazine has published since the 2000 year, articles, interiews, experience relacts who debate the knowledges and changes on the rural wolrd abou the light of Agroecology and rural sustainable development. In this sense, we propose a discussion about the Family farmes and rural developments. To base this photographic analysis, was used: documental analysis, contente analysis starting from the Reading of José de Souza Martins (2008) e Boris Kossoy (2008) who indicated some ways and strategies to appreciate this photographic images.
\end{abstract}

Key words: Family Farmer; Sustainable development; agroecology; EMATER/RS.

\title{
1. Introdução
}

Este artigo consiste em uma leitura das imagens fotográficas da revista Agroecologia e Desenvolvimento Rural Sustentável da EMATER-Empresa de Assistência Técnica e Extensão Rural/RS, que focaliza a agricultura familiar.

A revista foi lançada no ano de 2000. Segundo o seu editorial, ela surge a partir da necessidade de observar atentamente os rumos do desenvolvimento. Coincide também a virada do século. Identificamos talvez uma estratégia de germinar novas ideias e perspectivas, que orientem segundo seus editores, a Extensão Rural do Rio Grande do Sul.

Percebe-se, portanto que os modelos de desenvolvimento que estão vigentes, não atendem às necessidades humanas básicas, fracassando no combate à fome e a miséria, e também, colaborando com o desequilíbrio ambiental. Nesse cenário, a revista é um novo espaço de discussão teórica e prática sobre Desenvolvimento Rural Sustentável, Agricultura Sustentável, Agroecologia, Agricultura Familiar, da Extensão Rural e das relações sociais presentes nos processos de desenvolvimento rural.

Na leitura da revista desde o seu primeiro número, nosso objetivo é identificar as mudanças na imagem fotográfica do agricultor familiar, analisando as ausências e presenças na comunicação visuais percebidas a partir da mensagem proposta do que é mostrado, confrontando com o texto referente à fotografia e o seu contexto histórico-cultural.

Vale ressaltar que a revista não segue uma coerência em relação as suas edições. Por exemplo, no ano 2000, a revista teve apenas três edições, que foi a edição de janeiro a março, julho a setembro e a edição outubro a dezembro. No ano de 2001, a revista teve quatro edições janeiro a março, abril a junho, julho a setembro e a edição outubro a dezembro. Em 2002, também teve quatro edições janeiro a março, abril a junho, julho a setembro e a edição outubro a dezembro. De 2003 até 2010, a revista não publicou sequer uma edição. Em 2011, a revista retorna com a edição setembro a dezembro, com o título do editorial "Revista 
agroecológica e DRS: retomando o debate" neste editorial é reforçando o empenho da revista em retomar a discussão sobre o tema desenvolvimento rural sustentável. Em 2012, a revista tem a edição janeiro a abril, maio a agosto e setembro a dezembro. Em 2013, a revista tem apenas uma edição, justamente a edição de janeiro a novembro. Por fim, em 2014, houve duas edições, janeiro a abril e maio a agosto.

Devido justamente a falta de coerência nos meses de publicações da revista, analisaremos as edições janeiro a março dos anos 2000, 2001 e 2002, sendo analisado um artigo dessas edições para uma melhor compreensão dos conceitos propostos pela mesma, ou seja, o desenvolvimento rural sustentável, por meio da agricultura familiar.

As técnicas metodológicas aplicadas nesta pesquisa foram: análise documental através de Pimentel (2001), análise de conteúdo por meio de Silva, Gobbi, e Simão (2005) partindo da leitura de José de Souza Martins (2008) e Boris Kossoy (2008) que indicam formas e estratégias de análise de imagens fotográficas.

Martins (2008) apresenta a relação da imaginação com a prática da fotografia, tanto pelo fotógrafo profissional quanto pelo antropólogo e/ou sociólogo. Nesse sentido, Kossoy (2008) nos diz que as fotografias não escampam das condições materiais (tecnologia empregada) e imateriais (expressões simbólicas) referentes ao contexto histórico-social e a experiência de vida do fotógrafo.

\section{Referencial teórico}

A agricultura familiar não é uma novidade, mas nos últimos anos vem despertando o interesse acadêmico visto a grande quantidade existente de artigos, dissertações e teses. Além disso, o setor vem sendo amplamente discutido pelos orgãos governamentais. Vale ressaltar que todo este interesse acadêmico e político se deve ao fato do caráter reivindicatório dos movimentos socias, tais como associações, sindicatos e ONGs. Como, por exemplo, a implantação pelo poder público de uma política federal para atender a este campo, a criação do Programa de Fortalecimento da Agricultura Familiar - (PRONAF, 1996), a criação da Lei 11.326/2006, a primeira que atendeu às diretrizes para o campo (ALTAFIN, 2007).

A estrutura rural é extremamente complexa devido à grande diversidade do seu meio físico, ambiental e econômico. Uma vez que há diferentes tipos de agricultores, cada um possuindo interesses específicos, táticas de sobrevivência e de produção. Esses trabalhadores rurais resistem ao longo do tempo à exclusão das políticas governamentais e procuram dentro do sistema capitalista manter seu espaço competitivo de forma desigual com empreendimentos do agronegócio (SILVA \& JESUS, 2010). 

e-ISSN 2016/Atual: 2525-7870 | e-ISSN 2015/2016: 2447-018X

De acordo com o conceito do Dossiê Estatístico elaborado pelo Instituto Nacional de Colonização e Reforma Agrária - INCRA e o Fundo das Nações Unidas para a Agricultura e Alimentação - FAO (1996), a Agricultura Familiar é definida a partir de três características centrais:

\begin{abstract}
a) gestão da unidade produtiva e os investimentos nela realizados são feitos por indivíduos que mantém entre si laços de sangue ou de casamento; b) a maior parte do trabalho é igualmente fornecida pelos membros da família; c) a propriedade dos meios de produção (embora nem sempre da terra) pertence à família e é em seu interior que se realiza sua transmissão em caso de falecimento ou de aposentadoria dos responsáveis pela unidade produtiva (SILVA \& JESUS, 2010).
\end{abstract}

O princípio da agricultura familiar no Brasil surgiu no período colonial, em 1530, no Nordeste brasileiro, com a criação das capitanias hereditárias que funciovam por meio de trocas. A coroa portuguesa "dava" as terras para aqueles que se dispusessem a cultivá-las, em contra partida o latifundiário daria 1/6 do lucro da produtividade à coroa portuguesa (DINIZ, 2012).

Com a independência do país em 1822, a relação latifundiário e império tornou-se insustentavél. Isso porque, a partir daquele momento apenas quem comprasse a terra diretamente com o império seria de fato considerado o dono da mesma. Os tumultos aconteciam entre os antigos proprietários e os grileiros (homens que falsificavam documentos para que de forma ilegal se tornassem donos por direito de terras devolutas), visto que não envolviam trabalhadores rurais, pois em sua maioria eram escravos (DINIZ, 2012).

Em 1889, com a proclamação da República, pouco se aperfeiçoou na distribuição de terras. O poder político até a primeira metade do século XX continuou nas mãos dos donos das terras, também conhecido como os temidos coronéis do interior. Com toda essa conjuntura latifundiária, a agricultura nasce coberta de incertezas no plano econômico, político, judicário e social, colaborando para os meios de controle no trabalho e na produção agrícola, situação problemática no país (FAGUNDES, 2013).

Pode-se afirmar desde então, de maneira geral, que a agricultura camponesa nasceu no Brasil sob o signo da precariedade jurídica, econômica e social do controle dos meios de produção e especialmente, da terra; caráter extremamente rudimentar dos sistemas de cultura e das técnicas de produção; pobreza da população engajada nestas atividades, como demonstra a grande mobilidade espacial e a dependência ante a grande propriedade (LAMACHE, 1993 apud ALVES \& LIMA, 2008 p.40).

A agricultura familiar brasileira tem a sua maneira regional desde a sua concepção no Nordeste. Caracterizando-se pela extrema pobreza dos clãs que viviam perto das grandes 
extensões territoriais da monocultura. Construíam suas propriedades ao redor dos rios e cultivavam os produtos de subsistência. Esses "sitiantes", algumas vezes cultivavam nas terras dos grandes latifundiários e eram "protegidos" por eles. Essa solidariedade dos coronéis mudava quando a safra canavieira atingia boas safras. Os pequenos agricultores perdiam suas terras e não podiam participar do mercado (ALVES \& LIMA, 2008).

Em 6 de dezembro de 1948, após a Segunda Guerra Mundal, é criado a Associação de crédito e Assistência Técnica (ACAR) por meio do convênio o governo de Minas Gerais e a American International Association for Economic and Social Development (AIA). Esta instituição foi fundada pela família Rockefeller que sugere "estabelecer um programa de assistência técnica e financeira que possibilite a intensificação da produção agropecuária e a melhoria das condições econômicas e sociais da vida rural.”. Com isso, surgia oficialmente a Extensão Rural no Brasil (CALLOU, 2006).

Entre o final da década de 1950 e início de 1960, período este dos processos de industrialização e de urbanização no Brasil, as elites brasileira se viram na necessidade de um debate sobre as novas exigências mundiais de modernização da agricultura no Brasil. Que segundo o economista Celso Furtado é uma agricultura itinerante com duas vertentes: o progresso técnico e a distribuição da renda na marginalização social (WANDERLEY, 2009).

A política do agronegócio no Brasil foi implementada já no regime militar, quando o então, presidente Castelo Branco, encaminhou ao Congresso brasileiro, o projeto do Estatuto de Terra que tinha como objetivo, a industrialização da demanda na produção de alimentos, devido ao crescimento da população do país. Entretanto, esse projeto apresentou consequências sociais calamitosas pelo fato de $52 \%$ do contigente demográfico da agricultura no Brasil ser do Movimento dos Trabalhadores Sem Terra, atrapalhando assim, o desenvolvimento do setor. Vale ressaltar que nessa época, a empresa rural que é um empreendimento de pessoa física, pública ou privada com a exploração do imóvel rural, segundo os padrões fixados pelo poder público foi adotada como modelo de unidade de produção (WANDERLEY, 2009).

É válido ressaltar que entre 1960 a 1980, instituiu-se a ideia que para conquistar o crescimento e a modernização no campo brasileiro era necessário que difundisse o conceito de produtividade nas safras por meio de inovações tecnológicas. Fez parte desse processo persuadir os agricultores sobre os benefícios das inovações (LIMA \& ROUX, 2008).

Este tipo de comunicação nasce na conjunção de efeitos retóricos com fatores psicológicos, sociais e econômicos. Esta forma de comunicação utiliza-se da formação de slogans com a utilização de premissas e criação de persoagens que 
configuram tipos. Essa linguagem mexe com as emoções, com os juízos de valor com os conceitos já exisentes na sociedade. Levando o interlocutor a acreditar que precisa do produto ou serviço (LIMA \& ROUX, 2008, p.93).

A comunicação persuasiva adotou o modelo da Teoria da Difusão de Informações Everett Rogers, de 1969 para difundir através dos extensionistas a implantação do ideário da Revolução Verde e do seu objetivo de aumentar a produtividade agrícola e de pesquisas pelos orgãos públicos e instituições privadas. Mas essas conquistas acarretaram com um grande custo social, pois vieram juntamente com a concentração de terra e renda, exclusão do agricultor familiar no cenário político, crescimento na dependência de sementes transgênicas, o endividamento do agricultor na perda da safra, além dos impactos ambientais devido ao uso de insumos agrotóxicos (PIRES, 2010).

A formação dos movimentos ecológicos, também conhecido com agroecologia, surge no Brasil em 1970, com a luta das organizações não governamentais (ONGs), em participações nos fóruns mundias de debates, como por exemplo, a Conferência de Estocolmo, sobre o meio ambiente e o desenvolvimento (BENTHIEN, 2007).

A partir de 1980, a agroecologia é observada como uma perspectiva teórica alternativa. Fundamentada no "neonarodnismo ecológico" ou "neopopulismo ecológico", sendo analisado científicamente pelos autores, sobre a importância de conservar a biodiversidade ecológica e cultural, além do enfoque sistêmico para apreciação dos aspectos em relação à energia e os materiais no sistema econômico. Desta forma, o neopopulismo ecológico, mesmo criticando a ciência e as tecnologias modernas, não a nega, mas defende uma "modernidade alternativa", apartando a ideia de progresso de qualquer maneira sem respeitar as tecnologias proferidas modernas (CAPORAL \& COSTABEBER, 2000).

A expressão sociedade sustentável teve início no começo da década de 1980, por meio de Lester Brown, que definiu como a sociedade que é adequada de satisfazer as suas necessidades sem danificar as chances de sobrevivências das próximas gerações. O termo DS também surgiu nessa época devido ao agravamento da condição planetária, consequente da competição suicida pelo crescimento econômico que destrói os recursos naturais e começa a ocasionar grandes destruições e mortes (MILANEZ, 2003).

Ainda na década de 1980, a ONU cria a Comissão Mundial sobre Meio Ambiente e Desenvolvimento (CMMAD). Em 1987, essa comissão apresenta um estudo denominado Nosso Futuro Comum que tem como objetivo a qualificação e o crescimento econômico, capaz de contribuir para uma melhoria na qualidade de vida e a igualdade como princípio de 

e-ISSN 2016/Atual: 2525-7870 | e-ISSN 2015/2016: 2447-018X

repartição ambiental como fonte de solidariedade entre as gerações presente e futura (MILANEZ, 2003).

Em 1988, no Rio Grande do Sul o termo desenvolvimento sustentável se distingue da lógica oficial, que devido grande parte das realidades do período, disfarçava o problema demonstrado em um esforço para abordar o tema sem verdadeiramente sugerir as mudanças necessárias. Já em 1992, surge a agenda 21, ou seja, um documento consensual que sugere as ações que os países deveriam tomar para adotar as práticas sustentáveis no século XXI. Dois anos depois, no Rio Grande do Sul é realizado um encontro com o objetivo de reconhecer a preservação do meio ambiente como única maneira de preservação da natureza (MILANEZ, 2003).

Segundo Lima e Roux (2008) na década de 1990, o governo Fernado Collor de Mello, praticamente desmantelou a extensão pública rural, sem políticas públicas para apoiar o agricultor familiar. Apenas em 1995, o governo começa a observar este setor, com as estratégias de comunicação participativa e dialogada pelo novo Plano Nacional de Assistência Técnica e Extensão Rural (PNATER).

Em 2004, entra em vigor a nova política de Assistência Técnica e Extensão Rural Ater voltada para atender agricultores familiares, assentados, índios, quilombolas, pescadores artesanais, e outros, passando naquele momento a ser coordenados pela Secretaria da Agricultura Familiar - SAF, do Ministério do Desenvolvimento Agrário - MDA, com forme o Decreto $n^{\circ} 4.739$, de 13 de junho de 2003 (LIMA \& ROUX, 2008).

Outro fator preponderante na construção do entendimento da agricultura familiar são os territórios como meio de relações sociais na construção social das respectivas regiões. Além de ser um espaço geográfico como ambiente de aplicações de políticas públicas, empreendendo assim ações coletivas para o bem-estar social da coletividade (CAZELLA et al. 2009).

De acordo com Moraes e Curado (2004 apud ALVES et al. 2011) é essencial ponderar a viabilidade e a ampliação da agricultura familiar não apenas com o olhar econômicoprodutivo, mas, sobretudo, sócio-cultural e ambiental, pondo em debate as ações coletivas, o conjunto de necessidades e potencialidades que essas famílias percebem nesses ambientes, além da inquietação na importância da criação de um sistema de organização que faça as mudanças necessárias para a qualidade de vida desse povo.

Atualmente, a agricultura no Brasil está marcada pelos embates do agronegócio e da agricultura familiar. Diante desse contexto, o grande desafio é a preservação do patrimônio 
natural, a segurança alimentar, a quantidade e a qualidade dos alimentos, entre outras questões (WANDERLEY, 2009).

\section{Material e métodos}

\section{1 Área de estudo}

Fundada 26 de março de 1772, com o surgimento da Freguesia de São Francisco do Porto dos Casais, a cidade de Porto Alegre teve seu nome mudado um ano depois para Nossa Senhora da Madre de Deus de Porto Alegre (PREFEITURA DE PORTO ALEGRE, 2014). De acordo com o Instituto Brasileiro de Geografia e Estatística (IBGE), de 2010, o município conta com uma unidade territorial de 496, $682 \mathrm{~km}^{2}$, com densidade demográfica, 2.837,53(hab/Km²), e uma estimativa de população em 2014, de 1.472.482. O Índice de Desenvolvimento Humano Municipal de Porto Alegre (IDHM) é de 0,805 (IBGE, 2010).

O objeto de estudo é a revista Agroecologia e Desenvolvimento Rural Sustentável, produzida pela Empresa de Assistência Técnica e Extensão Rural do Estado do Rio Grande do Sul -EMATER- RS. Com publicações desde o ano 2000, a revista tem como objetivo o enfoque em artigos, entrevistas, relatos de experiência que debatem as experiências e transformações no mundo rural a luz da Agroecologia e do Desenvolvimento Rural Sustentável.

\subsection{Metodologia}

Este artigo tem como técnica metodológica a análise documental. Segundo Pimentel (2001), os documentos são apontamentos que demonstram informações em prol da concepção dos acontecimentos e relações, ou seja, permitem apreciar o período social e histórico das ações e recuperar os episódios e seus antecedentes, uma vez que se estabelecem em manifestações armazenadas dos aspectos da vida social de algum grupo.

Nesta pesquisa também foi adotada o método de análise de conteúdo por ser um conjunto de técnicas em análise das comunicações mirando obter, os procedimentos sistemáticos e utilitários de descrição com o conteúdo das mensagens, por meio de indicadores que admitam a inferência de conhecimentos referentes às categorias de produção e recepção dessas determinadas mensagens. Distingue-se, assim, por ser um método de tratamento da informação explícito nas mensagens (SILVA, GOBBI, \& SIMÃO, 2005).

Martins (2008) proporciona a relação da reflexão com a prática da fotografia, seja pelo fotógrafo profissional ou pelo antropólogo ou sociólogo. Dessa maneira, Kossoy (2008) 
afirma que as fotografias não escampam das categorias materiais (tecnologia empregada) e imateriais (expressões simbólicas) alusivas ao contexto histórico-social e a experiência de vida do fotógrafo.

A relação tempo/espaço na fotografia é suscitada tanto através da técnica quanto da sua forma de produção. Esses aspectos estão relacionados à racionalidade instrumental que conforme Zygmund Bauman (2001 apud OLIVEIRA, 2012), fez do homem o senhor de si e da natureza, que proveu a autonomia da ação, fazendo dele o único adequado em realizar a revolução imprescindível para o progresso ativo.

Deste modo, a pesquisa tem como finalidade identificar as transformações na imagem fotográfica do agricultor familiar por meio da revista Agroecologia e Desenvolvimento Rural Sustentável, avaliando as ausências e presenças na comunicação visual compreendida através da mensagem proposta do que é registrado, checando com o texto alusivo à fotografia e o seu contexto histórico-cultural.

\section{Análise e discussão dos artigos e fotografias da Revista Agroecologia e Desenvolvimento Sustentável}

\subsection{Breve relato sobre Revista Agroecologia e Desenvolvimento Sustentável}

Agroecologia, agricultura familiar, extensão rural, organização social, economia ecológica, reforma agrária, biodiversidade, balanços energéticos agropecuários, ecologia, impactos ambientais, metodologias participativas, agricultura/pecuária de base ecológica, tecnologia e sociedade, indicadores de sustentabilidade, comunicação rural, economia ecológica e economia política, conhecimento local, proteção etnoecológica, desenvolvimento endógeno e desenvolvimento local. Estes foram os conceitos que no ano 2000, a Emater do Rio Grande do Sul decidiu criar a revista Agroecologia e Desenvolvimento Sustentável, com o objetivo de contribuir para a divulgação no debate e na construção de conhecimentos na busca do desenvolvimento rural e nas agriculturas sustentáveis.

A revista surge em uma conjuntura em que nas últimas duas décadas a sociedade se preocupava com o rumo do desenvolvimento sustentável. Isso porque, a comunidade científica e política constataram que os modelos de estratégias de desenvolvimento, por meio do ideário da Revolução Verde não foram suficientes para resolver os problemas da fome e da miséria no ambiente rural brasileiro, e, além disso, resultou na degradação ambiental devido à utilização de insumos agrotóxicos. Dessa forma, a revista surge na busca da veiculação a respeito do tema sustentabilidade. 
A revista já conta com 17 edições. Com uma média de 30 a 60 páginas entre artigos, entrevistas, relatos de experiência que discutem as experiências e transformações no mundo rural por meio da Agroecologia e do Desenvolvimento Rural Sustentável. Ao longo dessas edições a capa sempre foi colorida. E o corpo editorial não adota legendas em suas fotografias dos artigos científicos.

Segundo Milanez (2003), a expressão sociedade sustentável surge no início da década de 1980, através de Lester Brown, que afirmou que como a sociedade deve se adequar para satisfazer as próprias necessidades sem comprometer as maneiras de sobrevivências das gerações futuras. Nessa mesma década, a Organizações das Nações Unidas (ONU) cria a Comissão Mundial sobre Meio Ambiente e Desenvolvimento (CMMAD), apresentando um estudo denominado Nosso Futuro Comum com a finalidade na qualificação e o crescimento econômico, apropriada na contribuição para um progresso na qualidade de vida e a igualdade como forma de repartição ambiental como meio de solidariedade entre as gerações presente e futura (MILANEZ, 2003).

Em 1988, no Rio Grande do Sul, a denominação desenvolvimento sustentável se assinala da lógica oficial, que devido a grande parte dos fatos do período, simulava o problema demonstrado em um esforço para acercar o tema sem realmente indicar as mudanças necessárias. Já em 1992, nasce a agenda 21, ou seja, um documento consensual que recomenda as ações que os países precisariam tomar para seguir os modelos sustentáveis no século XXI. Dois anos depois, no Rio Grande do Sul foi concretizado um encontro com a finalidade de adotar a preservação do meio ambiente como sendo a única maneira de preservação da natureza (MILANEZ, 2003).

\section{2. Análise fotográfica do artigo "Produção familiar, pós-modernidade e capitalismo possibilidades da agricultura independente"}

As políticas públicas voltadas à agricultura familiar apareceram no Brasil no início da década de 90, por dois fatores: a obrigação de intervenção estatal devido ao alto quadro de exclusão social e o crescimento dos movimentos sociais rurais. $\mathrm{O}$ aumento da violência, da insegurança e a miséria e nos centros urbanos fez com que também desenvolvesse a adesão da sociedade urbana em políticas de valorização no ambiente rural, com o objetivo de manter população no campo. Nesta conjuntura, em 1995 nasceu o Programa Nacional da Agricultura Familiar (PRONAF), devido à luta dos trabalhadores rurais com a finalidade de uma política pública peculiar e distinta para a agricultura familiar, com o intuito na criação deste programa, o governo federal atendeu de maneira distinta os mini e pequenos produtores rurais que 
realizam suas atividades através de emprego direto a própria força de trabalho e da própria família (CASTELÕES, 2002 apud ANTUNES et al., 2013).

Para Bianchini (2005 apud JUNQUEIRA \& LIMA, 2008), o mais relevante estudo em relação agricultura familiar e seu aporte ao desenvolvimento rural foi concretizado na esfera de um projeto em cooperação por meio do Fundo das Nações Unidas para a Agricultura e Alimentação - FAO e o Instituto de Colonização e Reforma Agrária - INCRA. O estudo FAO/INCRA começou em 1994 e foi finalizado 2000. De acordo com este estudo, há no Brasil 4.859.864 estabelecimentos rurais, destes, 4.139.369 empreendimentos são gerenciados pelos agricultores familiares ( $85 \%$ do total). O Valor Bruto da Produção Agropecuária (VBP) apurado nesse período foi de $\mathrm{R} \$ 47,8$ bilhões, sendo a agricultura familiar responsável por $\mathrm{R} \$$ 18,1 bilhões (38\% do total) desse valor. É válido ressaltar que o Plano Agrícola 2000/2001 que tem como finalidade principal nortear o produtor rural sobre as estruturas de política agrícola, que são alocados à disposição pelo governo federal, para ajudar eles a tomarem a melhor decisão na ocasião do plantio, teve um acréscimo de $\mathrm{R} \$ 2,7$ bilhões no montante em relação ao volume planificado para o Ano-Safra biênio 1999/2000 com juros em setenta e cinco por cento (MORAIS, 2000).

Nesse cenário, no ano 2000 surge a revista Agroecologia e Desenvolvimento Rural Sustentável, que logo em seu primeiro editorial deixa claro a preocupação com uma agricultura familiar voltada para o desenvolvimento sustentável. Sendo esse, por exemplo, o enfoque do artigo "Produção familiar, pós-modernidade e capitalismo possibilidades da agricultura independente". Esse artigo traz à tona a discussão sobre agricultura familiar como prática de geração de trabalho e renda, devido à comercialização dos produtos excedentes nas lavouras familiares.

Essa visão da agricultura familiar parte do pressuposto de uma agricultura cada vez mais forte e independente por meio de políticas públicas, com a participação dos atores sociais locais, com a utilização das pontencialidades endógenas da região contribuindo assim para o desenvolvimento da localidade.

$\mathrm{Na}$ primeira fotografia que analisamos do artigo observamos justamente o bem-estar social do homem do campo. Esse homem que por muitos anos sofreu com a falta de políticas públicas apropriadas para o meio rural que lutava contra diversos fatores adveros tais como: a seca, a falta de incentivo financeiro para plantar em suas lavouras ou também a falta de capital financeiro para proteger suas plantações das pragas daninhas. $\mathrm{Na}$ fotografia, o fotógrafo consegue demonstrar a felicidade do homem do campo que planta na busca de uma safra de subexistência e também na comercialização do excedente. 
A luz solar ao fundo da fotografia contempla o momento de registro na felicidade do homem do campo com o seu característico chapéu de palha, na colheita de suas leguminosas. Ainda é fato que o agricultor familiar não ter barganha financeira para competir com o gestor do agronegócio, mas quando ele reflete sobre o passado com momentos difíceis que muitas vezes não tinha sequer o que comer e que atualmente ele olha para a sua lavoura e observa o verde das suas plantações como é constatado pela fotografia. Esse homem rural tem mesmo de se orgulhar na fotografia ao fazer pose com as suas plantações nas mãos.

Segundo Martins (2008), por trás da fotografia, mesmo sendo aquela com a finalidade documental, existe um aspecto do fotográfo, uma maneira de relatar o que está sendo mencionado. Pois ao fotografar, o fotógrafo idealiza.

Essa percepção do fotográfo também é verificada na segunda fotografia. Nela outro homem do campo aparece colhendo as suas laranjas. As laranjas que tem um alto valor de vitamina $\mathrm{C}$, com alto interesse mercadológico em sua utilização não só pelo meio rural, mas também nos grandes centros urbanos vem ganhando cada vez mais espaço nas lavouras familiares.

O agricultor familiar que é um sábio devido ao conhecimento empírico é cada vez mais consciente da sua responsabilidade social, cultural e ambiental em relação às práticas sustentáveis em suas lavouras. As potencialidades endógenas estão cada vez mais em evidência no meio rural, não só na comercialização dos produtos, mas na produção deles também. O fotógrafo foi feliz na captação da fotografia ao constatar o cuidado do homem do campo, apalpando de forma cuidadosa suas laranjas. Essa fotografia demonstra a conscientização do produtor rural, na busca do meio rural cada vez mais justo.

De acordo com Kossoy (2008), centralizando nossa vigilância na imagem fotográfica atráves da representação expomos a consciência de que existe nela muito a desvendar além do que nos é dado na apreciação do documento iconográfico. Uma vez que ela resume no documento um pedaço da realidade.

\section{3. Análise fotográfica do artigo "Programa adubação verde do município de Porto}

\section{Mauá"}

Entre as décadas de 1960 a 1980, estabeleceu-se a ideia que para obter o desenvolvimento e modernização no campo rural brasileiro era imprescindível que disseminasse o conceito de produtividade nas lavouras por meio de novidades tecnológicas. Fez parte desta prática persuadir os agricultores sobre as benfeitorias das inovações (LIMA \& ROUX, 2008). 
A comunicação persuasiva abraçou o molde da Teoria da Difusão de Informações Everett Rogers acarretando em um grande custo social, uma vez que emanou com a centralização de terra e renda, exclusão do agricultor familiar no cenário político, aumento na dependência de sementes transgênicas, impactos ambientais pelo fato da utilização de insumos agrotóxicos e o endividamento do agricultor com a perda da safra (PIRES, 2010).

Essa conjuntura fez o governo federal desenvolver, no início da década de 90, uma política dual. Isso porque, de um lado, o Ministério da Agricultura, Pecuária e Abastecimento conservou, como finalidade central, a rivalidade do setor empresarial, elevando ao máximo as conveniências do agronegócio. Já do outro lado, o Ministério do Desenvolvimento Rural se ocupou oficialmente na reforma agrária e no desenvolvimento da agricultura familiar, adotando a importância social, ambiental e produtiva dessa fração para a sociedade em geral. Dessa forma, no quadro dos programas nacionais que se registraram em uma ótica de descentralização das decisões e de abertura às ações locais, em um conjunto de medidas, sobretudo nos domínios de aquisição e repartição de terras, no crédito rural, na infraestrutura rural e no apoio pela organização dos produtores (TONNEAU, 2005).

Foram com essa nova prática vingente que ocorreu o Programa adubação verde do município de Porto Mauá, localizado na Região Noroeste do Estado do Rio Grande do Sul. A cidade que se destaca pela produção e comercialização de grãos de milho e soja e atividade leiteira atravessou grandes dificuldades, pois as pequenas propriedades rurais da localidade sofreram com a desvalorização dos preços dos produtos agrícolas tradicionais produzidos na região, além também do alto custo com os insumos artificiais.

Nessa conjuntura, a prática da adubação verde (prática de acrescentar leguminosas na superfície do solo com o objetivo de enriquecê-lo nutricionalmente) é implementada como forma de desenvolvimento das lavouras de soja e milho. A utilização de outras espécies de adubação como a ervilhaca e o nabo forrageiro (plantas que auxiliam de maneira sustentável a adubação) também assumiram o papel importante no processo de redução dos custos da adubação artificial e na recuperação dos solos.

Em 1997, por meio da Secretária Municipal de Agricultura e EMATER, promoveu-se no Estado do Rio Grande do Sul a distribuição de sementes de mucuna, guandu-anão e crotalária a agricultores pertencentes ao Conselho Municipal de Desenvolvimento Rural com a finalidade de ampliar o conhecimento sobre estas espécies que se adequam bem com as condições climáticas e do solo para o seu desenvolvimento na região, encerrando assim a polarização do milho e da soja no município. Entretanto, os agricultores familiares tiveram certa resistência em relação a essas espécies. 

e-ISSN 2016/Atual: 2525-7870 | e-ISSN 2015/2016: 2447-018X

Nesse contexto, o Conselho Municipal de Desenvolvimento Rural, do município de Porto Mauá se viu na necessidade de adotar medidas de experimentação e divulgação das espécies tais como: troca e distribuição de sementes aos agricultores interessados, criação de unidades demonstrativas em todas as comunidades rurais, estímulo de emprego de plantas mucuna, guandu-anão, crotalária, abacaxi, banana e citros.

Com isso, foram conquistados resultados com os trabalhos de adubação verde. Tais como: o uso crotalária, mucuna, guandu-anão e feijão-de-porcos nas lavouras do município. Recuperação de áreas com lavouras de milho, soja ou outras espécies e produção de sementes da crotalária, mucuna, guandu-anão e feijão-de-porcos em outras lavouras.

A fotografia que analisamos datada em 2001, ano esse também da publicação do artigo retrata de forma explícita a nova perspectiva do agricultor familiar de Porto Mauá. Percebe-se a prática sustentável do agricultor familiar. Um homem com a vestimenta simples, humilde, mas com a conscientização da importância da adubação verde como prática sustentável.

Toda imagem é produzida segundo um processo de criação/construção que engloba componentes materiais (relativos à tecnologia empregada) e imateriais (relativos às intenções do fotográfo, ao seu repertório cultural, bagagem artística, convicções políticas, preconceitos internalizados, postura ideológica, enfim) (KOSSOY, 2008, p. 133).

O fotógrafo retrata o bem-estar social proveniente da adubação verde como maneira adequada nas lavouras, contribuindo assim para o desenvolvimento local e sustentável sem prejudicar as gerações futuras. Visto que, uma das característcas da agricultura familiar é exatamente o fato das terras passarem de posse dos pais para os filhos.

\section{4. Análise fotográfica do artigo "Agroecologia e saber ambiental"}

O termo agroecologia se difundiu nos anos 1980, devido aos trabalhos de Miguel Altieri e, em seguida, de Stephen Gliessman, ambos os pesquisadores de universidades estadunidenses e hoje avaliados como os principais nomes da "vertente americana" agroecológica (GUHUR \& TONÁ, 2012).

Altieri (1989 apud GUHUR \& TONÁ, 2012), definiu agroecologia na primeira publicação mais metódica sobre o tema, como sendo uma agricultura alternativa. Já como ciência, a agroecologia surge na busca por ultrapassar o conhecimento fragmentário, em benefício de um enfoque integrado. Seu conhecimento se estabelece, mediante ao intercâmbio entre distintas disciplinas, para entender o funcionamento dos ciclos minerais, os processos 
biológicos, as transformações de energia e as relações socioeconômicas, no diagnóstico nas diferentes ações que interferem na atividade agrícola.

A agroecologia incentiva os agricultores a resgatarem seu conhecimento do campo, para ampliar o bem-estar ecológico sem a necessidade de insumos químicos e energéticos externos. Trazendo o equilíbrio na relação dos componentes da natureza entre as plantas, solo, nutrientes, luz solar, umidade e organismos coexistentes. No intuito sempre de restaurar os estresses sofridos no meio ambiente. Além disso, a intenção é que os agricultores sejam os agentes de seu próprio desenvolvimento. Sendo agroecologia a ferramenta metodológica para a realização da inclusão da comunidade como seiva geradora para o amparo das expectativas colocadas nos projetos de desenvolvimento (CARMO, 2008).

O agricultor familiar, por ter o conhecimento das condições ambientais locais, além da pouca condição financeira que possui, é considerado peça-chave na prática da produção agrocológica (MOREIRA, 2000). Por sua vez, a etnociência tem revelado que o ambiente composto pelos indivíduos tem como objetivo resgatar os entendimentos tradicionais, ou seja, a relação da sociedade com o meio ambiente (DIEGUES, 1996 apud BARENHO e MACHADO, 2007). Por meio de uso de recursos naturais, a sociedade construiu um território rentável de diversidade biológica e cultural (DIEGUES, 2004 apud BARENHO e MACHADO, 2007).

Nesse contexto, é publicado o artigo "Agroecologia e saber ambiental”, na edição janeiro e março de 2002, da revista Agroecologia e Desenvolvimento Rural e Sustentável. Isso porque, a transformação produtiva no meio rural, por meio da agroecologia também é fonte de geração de emprego e renda para a população local que apesar da Revolução Verde ter conquistado resultados relevantes na produtividade agrícola essas conquistas ocorreram a um alto custo social, pois chegaram por meio de concentração do território e do capital, expulsando assim, o homem do campo para as grandes cidades na busca de melhores condições de vida que culminou com a favelização nos conglomerados urbanos.

A agroecologia utiliza a potencialidade endogéna da região, contribuindo assim para uma participação democrática e participativa da população local. Além disso, o movimento ambiental está abrindo novas vias para reverter a degredação ecológica, a congestão urbana, a concentração industrial e a concentração de poder proporcionada principalmente pelos gestores do agronegócio.

A implementação da prática agroecológica é percebida na fotografia desse artigo, em que homem e mulheres do campo utilizam a água do lago para pescar, lavar roupa, ou até mesmo bebê-la. Para utilizar a água dessa forma, é preciso de um alto grau de conscientização 
da população para que se mantenha um ambiente ecológico de forma que não comprometa a vida útil do solo, plantas e água. A agricultura agroecológica vem a cada ano se solidificando como método sustentável. O ângulo escolhido destaca, justamente, esse bem-estar social provocado pela agroecologia.

Segundo Martins (2008), a fotografia são documentos importantes para as ciências sociais, para analisar as mentalidades e os relacionamentos entre as relações sociais e consciência social. É nessa superfície, ainda, que ela pode virar antropológicamente documental.

Outra fotografia também que merece uma análise documetal é na estufa de rosas do campo. Analisar essa fotografia por meio das lentes do fotógrafo é percebido que a luz solar dar um realce a beleza do local. Esteticamente talvez essa fotografia seja uma das mais belas da revista Agroecologia e Desenvolvimento Rural e Sustentável. A sutileza, a delicadeza, e até mesmo o viés romanticista proporcionado pelo fotógrafo nos deixa mais convicto, sobre o quão é importante à preservação da natureza pelo homem. Talvez se o agricultor, dono dessa estufa fosse apenas um gestor do agronegócio, essa paisagem não fosse tão bela, pois o agronegócio tem como principal finalidade o retorno fincanceiro e não a preservação do meio ambiente. Olhar para essa fotografia nos deixa um pouco mais românticos.

Para Kossoy (2008), não há como negar que uma única imagem é dotada de informações riquíssimas sobre o contexto em que foi realizada. Sua superfície iconográfica, seu componente, aborda muitos fatos sobre a época, a técnica, a estética e o seu autor, das informações que a estabelecem.

\section{Conclusão}

Observou-se que a revista Agroecologia e Desenvolvimento Rural Sustentável conseguiu disseminar na sociedade, sobretudo na comunidade acadêmica a importância de práticas ecológicas sustentáveis. Isso porque, devido a Revolução Verde o ambiente rural teve a degradação do solo pelo fato da utilização e insumos inapropriados e, além disso, a estagnação social também devido ao ideário de Rogers uma vez que nem todos os agricultores, especialmente o familiar teve condições financeiras para se adequear as práticas do agronegócio.

Constatou-se que a utilização da prática agroecológica é forma mais adequada de se utilizar o ambiente rural sem comprometer as gerações futuras. Contribuindo assim, para o desenvolvimento e o bem-estar, pois com o emprego de políticas públicas apropriadas e a participação da família o meio rural se torna mais justo e igualitário. 
RELACult - Revista Latino-Americana de Estudos em Cultura e Sociedade

Revista Latinoamericana de Estudios en Cultura y Sociedad | Latin American Journal of Studies in Culture and Society V. 02, Ed. Especial, dezembro, 2016, p. 466-484| periodicos.claec.org e-ISSN 2016/Atual: 2525-7870 | e-ISSN 2015/2016: 2447-018X

Verificou-se que a imaginação fotográfica emprega uma maneira de produção fotográfica, com a perspectiva e o apelo aos recursos técnicos indicando e definindo, assim o que na fotografia precisa fazer parte e como ela deve fazer parte. É preciso ressaltar, que em relação análise das fotografias da revista Agroecologia e Desenvolvimento Rural Sustentável a compreensão dos signos fotográficos é um pouco comprometida, devido às fotos serem expostas em preto e branco ao longo das edições da revista.

A pesquisa permite concluir que a agricultura familiar por meio de práticas de desenvolvimento sustentáveis, notadamente agroecológicas atráves da análise fotográfica é uma maneira de perceber o desenvolvimento do campo agrário brasileiro.

\section{Referências}

ALTAFIN, Iara. Reflexões sobre o conceito de agricultura familiar. Redes Regionais de Agroecologia, Embrapa, 26 abr. 2007. Disponível em:

<http://mstemdados.org/sites/default/files/Reflex\%C3\%B5es\%20sobre\%20o\%20conceito\%2 0de\%20agricultura\%20familiar\%20-\%20Iara\%20Altafin\%20-\%202007_0.pdf >. Acesso em: 09 nov. 2014.

ALVES, Ademário. LIMA, Hunaldo. Agricultura familiar. Disponível em: <http://linux.alfamaweb.com.br/sgw/downloads/141_113859_AgriculturaFamiliar.pdf >. Acesso em: 09 nov. 2014.

ALVES, V. et al. O Associativismo na Agricultura Familiar dos Estados da Bahia e Minas Gerais: potencialidades e desafios frente ao Programa de Aquisição de Alimentos (PAA).In:V Encontro Nacional de Pesquisadores em Gestão Social (ENAPEGS), 5.,2011. Anais... Florianópolis: Universidade do Estado de Santa Catarina (UDESC) / Centro de Ciências da Administração e Sócio-Econômicas (ESAG), 2011. p. 4-9.

ANTUNES, R. L. et al. Programa nacional de crédito da agricultura familiar e impactos nas economias locais no estado do Paraná. Economia \& Região., Londrina, v.1, n.1, jan./jul. 2013. p. 69-90.

BARENHO, Cíntia Pereira.; MACHADO, Carlos RS. Contribuições do Marxismo e da Etnoecologia para o estudo das relações socioambientais. In: V Colóquio Internacional Marx e Engels, 5., 2007, Campinas. Anais... Campinas: Centro de Estudos Marxistas (Cemarx) da Unicamp, 2007. p. 2.

BENTHIEN, Patrícia Faraco. ONGs e agroecologia no Brasil. Brasileira de Agroecologia., Rio Grande do Sul, v.2, n.1, fev. 2007. p.25.

CARMO, Maristela Simões do. Agroecologia: novos caminhos paraa agricultura familiar. Tecnologia \& Inovação Agropecuária., São Paulo, v.1, n.2, p. 34-38, dez. 2008.

CALLOU, Angelo Brás Fernandes. Extensão rural: polissemia e resistência. In: XLIV Congresso da Sociedade Brasileirade Economia e Sociologia Rural (Sober), 44., 2006, 
Fortaleza. Anais... Fortaleza: Questões Agrárias, Educação no Campo e Desenvolvimento, 2006. p.6.

CAPORAL, F. R.; COSTABEBER, J. A. Agroecologia e desenvolvimento rural sustentável: perspectivas para uma nova extensão rural. Agroecologia e Desenvolvimento Rural Sustentável., Porto Alegre, v.1, n.1, jan./mar. 2000. p.25-27.

CAZELLA, Ademir.A.; BONNAL, Philippe.; MALUF, Renato.S. (Orgs.) Agricultura familiar, multifuncionalidade e desenvolvimento territorial no Brasil. Rio de Janeiro: Mauad X, NEAD, IICA, 2009. p. 47-56.

DINIZ, Ellen Rúbia. AGRICULTOR FAMILIAR. PRONATEC. Disponível em: 〈http://200.17.98.44/pronatec/wp-content/uploads/2012/07/af.pdf >. Acesso em: 09 nov. 2014. FAGUNDES, L. A. F. Desenvolvimento agrário: o contexto da ocupação da terra nos assentamentos rurais do município de matos costa-sc. 2013. 114f. Dissertação (Mestrado em desenvolvimento regional), Universidade do Contestado - UnC, Santa Catarina. 2013.

GUHUR, Dominique Michèle Perioto.;TONÁ, Nilciney. Agroecologia. In: Caldart, R. S. et al. (org.) Dicionário da educação no campo. Rio de Janeiro, São Paulo: Escola Politécnica de Saúde Joaquim Venâncio, Expressão Popular, 2012. p. 59-67.

\section{INSTITUTO BRASILEIRO DE GEOGRAFIA E ESTATÍSTICA. IBGE CIDADES. Disponível em: $<$ http://www.cidades.ibge.gov.br/xtras/perfil.php?lang=\&codmun=431490\&search=rio- grande-do-sul|porto-alegre $\geq$. Acesso em: 09 nov. 2014.}

JUNQUEIRA, Clarissa Pereira.; Lima, Jandir Ferrera de. Políticas públicas para a agricultura familiar no Brasil. Semina: Ciências Sociais e Humanas. Londrina, v. 29, n. 2, jul./dez. 2008. p. 159-176.

KOSSOY, Boris. Fotografia e paisagem: o explícito e o oculto nas representações fotográficas. Comunicação e Linguagens., Lisboa, n. 39. 2008. p. 133-142.

LIMA, Irenilda de Souza; ROUX, Bernard. As Estratégias de comunicação nas políticas públicas de assistência técnica e extensão rural para agricultura familiar no Brasil. In: CIMADEVILLA, Gustavo. Comunicación, Tecnologia y desarrollo. Argentina: Editora da Universidad Nacional de Rio Cuardo. 2008. p. 91-98.

MARTINS, José de Souza. Sociologia da fotografia e da imagem. São Paulo: Contexto, 2008.

MILANEZ, Francisco. Desenvolvimento sustentável. In: CATTANI, Antonio David (Org.). A outra economia. Porto Alegre: Veraz Editores, 2003. p. 76-84.

MORAIS, Marcus Vinicius Pratini de. Plano Agrícola Ano Safra 2000/2001.

Ministro da Agricultura e do Abastecimento. Disponível em:

$<$ http://www.agricultura.gov.br/arq_editor/file/Ministerio/planos\%20e\%20programas/pap\%20 2000\%202001.pdf>. Acesso em: 09 nov. 2014. 
RELACult - Revista Latino-Americana de Estudos em Cultura e Sociedade

Revista Latinoamericana de Estudios en Cultura y Sociedad | Latin American Journal of Studies in Culture and Society

V. 02, Ed. Especial, dezembro, 2016, p. 466-484| periodicos.claec.org

MOREIRA, Roberto J. Críticas ambientalistas à Revolução Verde. Estudos Sociedade e Agricultura, Rio de Janeiro, n.15, out. 2000. Disponível em:

<http://r1.ufrrj.br/esa/V2/ojs/index.php/esa/article/view/176/172 >. Acesso em: 30 out. 2014.

OLIVEIRA, Larissa Pascutti de. Zygmunt Bauman: a sociedade contemporânea e a sociologia na modernidade líquida. Sem aspas, Araraquara., São Paulo, v.1, n.1. 2012. p. 25-36.

PIMENTEL, Alessandra. O método da análise documental: seu uso numa pesquisa historiográfica. Cadernos de Pesquisa., n. 114, nov. 2001. p. 179-195.

PIRES, Maria Luiza Lins e Silva. Cooperativismo e dinâmicas produtivas em zonas desfavorecidas: o caso das pequenas cooperativas agrícolas do sul da França. Sociologias., Porto Alegre, v.13, n.26, jan./abr. 2011. p. 230.

PREFEITURA DE PORTO ALEGRE. Histórico da cidade. Disponível em: $\leq$ http://www2.portoalegre.rs.gov.br/turismo/default.php?p_secao=257>. Acesso em: 09 nov. 2014.

SILVA, Cristiane Rocha; GOBBI, Beatriz Christo; Simão, Ana Adalgisa. O uso da análise de conteúdo como uma ferramenta para a pesquisa qualitativa: descrição e aplicação do método. Lavras. Minas Gerais, v.7, n.1. 2005. p.53-66.

SILVA, José Ribeiro da. JESUS, Paulo de. Os desafios do novo rural e as pespectivas da agricultura familiar no Brasil. In: V Congresso Norte-Nordeste de Pesquisa e Inovação (CONNEPI), 5., 2010, Maceió. Anais... Maceió: Centro de Convenções de Maceió, 2010. p.1-2.

TONNEAU, Jean-Philippe.; AQUINO, Joacir Rufino de.; TEIXEIRA, Olívio Alberto. Modernização da agricultura familiar e exclusão social: o dilema das políticas agrícolas.

Cadernos de Ciência \& Tecnologia., Brasília, v. 22, n. 1, jan./abr. 2005. p. 67-82. WANDERLEY, Maria Nazareth Baudel. O agricultor familiar no Brasil: um ator social da construção do futuro. In:: Petersen, Paulo (org.). Agricultura familiar camponesa na construção do futuro. Rio de Janeiro: AS- PTA, 2009. p. 33-45. 